\title{
Modelling spatial variations of novel coronavirus disease (COVID-19): evidence from a global perspective
}

\author{
Isaac Appiah-Otoo (i) Matthew Biniyam Kursah $\mathbb{B}$
}

Accepted: 18 April 2021/Published online: 24 April 2021

(C) The Author(s), under exclusive licence to Springer Nature B.V. 2021

\begin{abstract}
In late December 2019, strange pneumonia was detected in a seafood market in Wuhan, China which was later termed COVID-19 by the World Health Organization. At present, the virus has spread across 232 countries worldwide killing 2,409,011 as of 17 February 2021 (9:37 CET). Motivated by a recent dataset, knowledge gaps, surge in global cases, and the need to combat the virus spread, this study examined the relationship between COVID-19 confirmed cases and attributable deaths at the global and regional levels. We used a panel of 232 countries (further disaggregated into Africa-49, Americas-54, Eastern Mediterranean-23, Europe-61, Southeast Asia-10, and Western Pacific-35) from 03 January 2020 to 28 November 2020, and the instrumental variable generalized method of moment's model (IV-GMM) for analysing the datasets. The results showed that COVID-19 confirmed cases at both the global and regional levels have a strong positive effect on deaths. Thus, the confirmed cases significantly increase attributable deaths at the global and regional levels.
\end{abstract}

I. Appiah-Otoo ( $\square)$

School of Management and Economics, Center for West

African Studies, University of Electronic Science and

Technology of China, Chengdu, China

e-mail: appiahotooi@yahoo.com

M. B. Kursah

Department of Geography Education, University of Education, Winneba (UEW), Box 25, Winneba, Ghana e-mail: mkursah@uew.edu.gh
At the global level, a $1 \%$ increase in confirmed cases increases attributable deaths by $0.78 \%$. Regionally, a $1 \%$ increase in confirmed cases increases attributable deaths by $0.65 \%$ in Africa, $0.90 \%$ in the Americas, $0.67 \%$ in the Eastern Mediterranean, $0.72 \%$ in Europe, $0.88 \%$ in Southeast Asia, and $0.52 \%$ in the Western Pacific. This study expands the understanding of the relationship between COVID-19 cases and deaths by using a global dataset and the instrumental variable generalized method of moment's model (IVGMM) for the analysis that addresses endogeneity and omitted variable issues.

Keywords Coronavirus - Novel coronavirus (SARS-COV-2) · COVID-19 - Spatial variation · Global pandemics

\section{Introduction}

In late December 2019, strange pneumonia (coronavirus disease) was detected in a seafood market in Wuhan, China which was later termed COVID-19 by the World Health Organization (WHO) (Desjardins et al., 2020; Sarkodie \& Owusu, 2020). COVID-19 is a viral infection that causes severe acute respiratory syndrome with serious clinical signs such as dry cough, fever, respiratory disorders, dyspnea, and pneumonia and may end up in advanced respiratory 
collapse and death (Coccia, 2020). At present, the virus is spreading at an exponential rate worldwide (Adekunle et al., 2020) with human-to-human-transmission, temperature, and air pollution being the main diffusion channels (Coccia, 2020; Roy, 2020). According to the WHO COVID-19 Dashboard (https://covid19.who.int/), the global confirmed cases stood at 109,068,745 (Africa-2,750,050, Americas48,637,963, Eastern Mediterranean-6,074,987, Europe-36,806,380, South-East Asia-13,248,512 and the Western Pacific-1,550,108, whilst global deaths stood at 2,409,011 (Africa-69,178, Americas 1,149,442, Eastern Mediterranean-140,510, Europe-818,993, Southeast Asia-203,604 and the Western Pacific27,271) as of 17 February, 2021 (9:37 CET).

Accordingly, recent scholars have modelled the relationship between COVID-19 confirmed cases (henceforth cases) and attributable deaths (henceforth deaths) with the literature having a consensus that cases spur deaths (Adekunle et al., 2020; Sarkodie \& Owusu, 2020). However, these studies are insufficient and suffer from the problem of historical data. For instance, Sarkodie and Owusu (2020) used a panel of 31 provinces in China for the period 21 January 2020, to 20 February 2020 to examine the relationships between cases and deaths and found that cases significantly increase deaths in China. Adekunle et al. (2020) used a panel of 52 Africa countries for the period 15 March 2020 to 14 April 2020 to examine the relationship between cases and deaths and found that cases significantly increase deaths in Africa. With COVID-19 being a global pandemic (WHO) and the surge in global cases, understanding the impact of cases on deaths at the global and regional levels using a recent dataset will enable policymakers to adopt the best strategies to mitigate this global pandemic, hence our objective.

We contribute to the literature examining the relationship between cases and deaths in the following three ways. First, we used a global dataset. Our dataset constitutes 232 countries further disaggregated into Africa-49, Americas-54, Eastern Mediterranean-23, Europe-61, Southeast Asia-10, and Western Pacific-35 to reduce homogeneity in the dataset. Furthermore, we used a more recent dataset. Our dataset ranges from 03 January 2020 to 28 November 2020. Finally, we used the instrumental variable generalized method of moment's model (IV-GMM) for our analysis. This model addresses endogeneity and omitted variable issues (Acheampong et al., 2019; Appiah-Otoo \& Acheampong, 2021; Appiah-Otoo \& Song, 2021).

We tested the null hypothesis that cases do not significantly increase deaths in both the full and regional samples. By using the IV-GMM model and the fixed-effect model, the null hypothesis was rejected.

The rest of the studies follow: "Review of related literature" section presents a brief literature review and "Methodology" section presents the methodology, which constitutes the data and empirical model. "Results and discussion" section presents the results and discussion, whilst "Conclusion and policy recommendations" section presents the conclusion and policy recommendations.

\section{Review of related literature}

Since the detection of COVID-19 in late 2019, studies have applied new applications, models, and statistical techniques to unravel the nexus between cases and deaths (albeit mostly on a regional and national basis), the transmission factors and mechanisms, and the detection of clusters (e.g., Adekunle et al., 2020; Coccia, 2020; Desjardins et al., 2020; Huang et al., 2021; Roy, 2020; Sarkodie \& Owusu, 2020). For example, Adekunle et al. (2020) constructed the spatial variations of clusters that examined the link between deaths and cases of COVID-19 in Africa. Aslam et al. (2021) designed a fractional-order model with Caputo Fabrizio fractional derivative operator of order for the COVID-19. The work has the potential in assisting governments to find useful and practical ways for controlling the pandemic. A susceptible exposed infectious recovered model and isolation measures for evaluating COVID-19 cases have also been proposed (Huang et al., 2021). It is based on government prevention and control policies. The model results showed an early peak of the virus and a reduced number of cases at the peak as the intensity of prevention and control measures increase. Desjardins et al. (2020) spatio-temporal model did not only showed COVID-19 clusters but also detected the emerging clusters. This can inform public health officials and stakeholders about where to improve the allocation of resources and testing sites. It will also assist in identifying where to implement stricter quarantines or travel bans. On the other hand, a 
developed time-series and panel data model has been used to construct conceptual tools (Sarkodie \& Owusu, 2020). This model was then used to examine the relationship between COVID-19 cases and deaths. The effect of cases on deaths was shown to be heterogeneous across the Provinces in China. Thus, cases and deaths were not proportionately universal in the Provinces as an increase in cases by $1 \%$ increased deaths by $\sim 0.10 \%$ to $\sim 1.71 \%$. Modelling pandemic datasets in this way help to understand the impact of cases on deaths at all level will enable policymakers to adopt the best strategies to mitigate this pandemic. This is because the analysis of the dynamics of diseases and effective control measures or policies play a vital role in the prevention of diseases (Aslam et al., 2021).

Other models and statistical tools have been employed to explored COVID-19 cases, deaths, or both. Yahya et al. (2021) applied three artificial neural networks (ANN) functions to predict the spread of COVID-19 cases and found that the spread severity is expected to intensify in the next few months (six) by $17.1 \%$ while the average deaths by $8.3 \%$ with a model performance efficiency reaching $81.6 \%$. The model provided the expected cases and deaths due to the virus for authorities to better plan for the management of the case and death counts in the future. Aronu et al. (2021) explored the survival of COVID-19 using the autoregressive integrated moving average (AIMA) model and time-series data for analyzing the survival rate of COVID-19. The study found that the average survival rate was $27.5 \%$ while the median survival rate was 25.4\%. Such modelling helps the decision-makers with appropriate interventions to combat the pandemic. Similarly, Kodge (2021) applied geo-visualization techniques for studying detailed scenarios of COVID-19 cases. This enabled the visualization of the virus case and death counts on a regional and countrywide basis for tailoring control measures to areas that most required them.

The linear relationship between environmental pollution proxies and COVID-19 cases and deaths has also been studied. With Kendall and Spearman correlation methods, a study found that $\mathrm{PM}_{10}, \mathrm{PM}_{2.5}$, sulfur dioxide, and nitrogen dioxide were significantly correlated with COVID-19 cases and deaths (Bashir et al., 2020b). Similarly, Magazzino et al. (2021) concluded that $\mathrm{PM}_{2.5}$ and $\mathrm{NO}_{2}$ are the most significant pollutant agents responsible for facilitating COVID-
19 deaths. Therefore, reducing human exposure to these pollutants will enhance the efforts of defeating the virus. Coccia (2020) model showed that COVID19 transmission has a high association with air pollution of cities in the presence of low wind speed. That is, cities that had high air pollution and low wind speed had a higher transmission of the virus. Jain et al. (2021) used advanced econometric techniques to examine the relationship between COVID-19 cases, deaths, and meteorological factors. COVID-19 cases and air pollutants were shown to have a statistically significant impact on COVID-19 deaths. Thus, pollution control or reduction, while being very good for the general health of humans, will be a COVID-19 reduction strategy as well.

The link between COVID-19 cases and deaths, and the environmental and meteorological variables such as temperature, humidity, and air quality have also gained research attention. For instance, an inverse relationship between the wind speed and humidity on the other hand, and COVID-19 cases on the other has been reported (Ahmadi et al., 2020). Likewise, COVID-19 daily deaths had a direct relationship with the diurnal temperature range and an inverse relationship with relative humidity (Ma et al., 2020). The average temperature, minimum temperature, and air quality had significant associations with COVID-19 cases and deaths (Bashir et al., 2020a). In a similar pattern, Sharma et al. (2020) found a significant positive association between the minimum and maximum temperature, humidity, and COVID-19 cases. Thus, these environmental variables are key to reducing the cases and deaths due to the virus. Similarly, Roy (2020) modelled and explored the impact of the temperature on the spread and vulnerability of COVID-19. The temperature variable played a vital role in transmitting the virus. Thus, the moderately cool environment was the most conducive for the virus spread while the risk of spread was reduced greatly for warm places and countries. Intuitively, with the variability of temperature, countries, and regions can switch from one vulnerability state to another (Roy, 2020).

Population activities and dynamics and their link with COVID-19 cases and deaths have also been studied. Cunningham (2021) examined the countylevel associations of physical activity with COVID-19 cases and deaths. The study found that the physical activity rates at the county level had a significant 
inverse relationship with COVID-19 cases and deaths. Thus, the physical activity rate was associated with decreased case and death counts. This offered empirical evidence of the benefits of county-level physical activity for mitigating the pandemic impacts. This might be due to the health benefits and boost of the human system due to body exercise or activity. Other population variables such as population density and movement have been linked to the virus case count. Using the Sobol-Jansen and partial correlation methods, Ahmadi et al. (2020) established that intraprovincial movement and population density have a positive effect on COVID-19 cases. Gaskin et al. (2021) found that COVID-19 cases and deaths are positively connected to the proximity and passenger volume of the nearest airport. The number of COVID19 cases and deaths were positively associated with the number of airports, the number of train stations, and the percent of adults using the public transportation system. Thus, reducing population movement and transits was key to defeating the virus. This has justified the frequent use of lockdowns in most countries as a combating mechanism of the virus.

The knowledge gained from these studies can be used to better understand the dynamics of the virus and help stem the pandemic, which is not only having a toll on lives but is also fast ravaging world economies. Our study adds to the knowledge of the dynamics of the pandemic from the global and regional levels.

\section{Methodology}

Data

We used daily unbalanced data for 232 countries (further disaggregated into Africa-49, Americas-54, Eastern Mediterranean-23, Europe-61, Southeast Asia-10, and Western Pacific-35) for the period 03 January 2020 to 28 November 2020. The data consisted of cases and deaths. We acquired the data from the WHO Coronavirus Disease (COVID-19) Dashboard. ${ }^{1}$ The spatial distribution of global COVID-19 cases and deaths are shown in Fig. 1.

Table 1 presents the descriptive statistics of the variables over the study period. The result indicates on average global cases stood at $4.48 \%$ with an average number of deaths of $2.21 \%$. At the regional level, the Eastern Mediterranean had the highest average cases (5.10\%) followed by Southeast Asia (4.92\%), Europe (4.90\%), the Americas (4.79\%), the Western Pacific (3.39\%), and Africa having the lowest average cases $(3.35 \%)$. South-East Asia had the highest average deaths $(3.34 \%)$, followed by the Americas (2.86\%), Europe (2.24\%), Eastern Mediterranean (2.08\%), the Western Pacific (1.51\%), and Africa having the lowest average deaths $(1.11 \%)$. The standard deviations of the variables show that they are not volatile, except for deaths in Africa which were slightly higher than the mean.

Figure 2 presents the bivariate relationship between cases and deaths for Africa, the Americas, Eastern Mediterranean, Europe, Southeast Asia, Western Pacific, and the Global sample. The results indicate that there exists a strong positive relationship between cases and deaths at both the global and regional levels.

\section{Empirical model}

Following Sarkodie and Owusu (2020) and Adekunle et al. (2020), the empirical model underpinning this study is as follows:

$\ln$ deaths $_{i t}=b_{o}+b_{1} \ln$ cases $_{i t}+\varepsilon_{i t}$

where $\ln$ deaths $_{i t}$ represents COVID-19 total number of attributable deaths, whilst ln cases $_{i t}$ signifies COVID-19 total number of confirmed cases. The parameter $b_{o}$ denotes the constant, whilst $b_{1}$ denotes the long-run elasticity estimates of deaths to cases. The subscript $i$ and $t$ signify time and countries. $\varepsilon_{i t}$ signifies the error term of each observation. This study aims to estimate $b_{1}$. We expect $b_{1}$ to have a significant positive effect on deaths.

Given omitted variables, and endogeneityproblems associated with Eq. (1), we used the IV-GMM model for our analysis. This model addresses these challenges (Acheampong et al., 2019; Appiah-Otoo \& Acheampong, 2021; Appiah-Otoo \& Song, 2021). We further used the fixed effects (FE) model for robust testing.

$\overline{1}$ https://covid19.who.int/ retrieved November 28, 2020. 

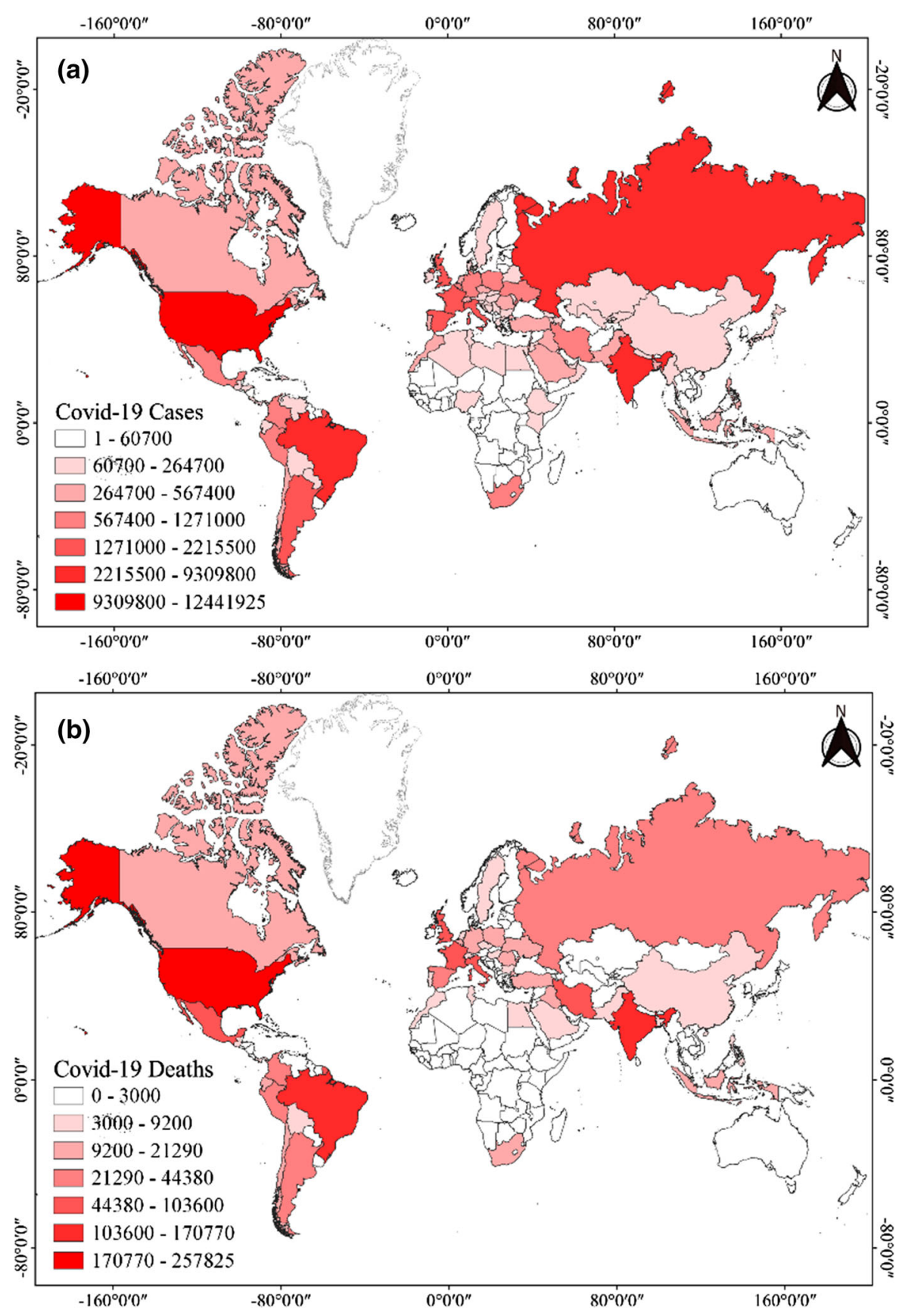

Fig. 1 The spatial distribution of global COVID-19. a Cases, b deaths as of November 28, 2020

\section{Results and discussion}

Global analysis

Table 2 presents the IV-GMM results. The results indicate that cases at both the global and regional levels have a strong positive effect on deaths. At the global level, a $1 \%$ increase in cases increases deaths by $0.78 \%$ at the $1 \%$ significance level. This implies that a $10 \%$ rise in cases increases deaths by $7.8 \%$. At the regional levels, a $1 \%$ increase in cases increases deaths by $0.65 \%$ in Africa, $0.90 \%$ in the Americas, $0.67 \%$ in 
Table 1 Descriptive statistics

\begin{tabular}{|c|c|c|c|c|c|}
\hline Variables & Obs. & Mean & SD & Min. & Max \\
\hline \multicolumn{6}{|l|}{ Global } \\
\hline lndeaths & 23,604 & 2.205 & 1.804 & 0 & 8.765 \\
\hline lncases & 40,212 & 4.482 & 2.525 & 0 & 12.683 \\
\hline \multicolumn{6}{|l|}{ Africa } \\
\hline lndeaths & 3269 & 1.109 & 1.226 & 0 & 6.349 \\
\hline lncases & 7866 & 3.351 & 1.861 & 0 & 9.543 \\
\hline \multicolumn{6}{|l|}{ Americas } \\
\hline lndeaths & 5199 & 2.860 & 2.096 & 0 & 8.765 \\
\hline lncases & 8185 & 4.789 & 2.88 & 0 & 12.683 \\
\hline \multicolumn{6}{|c|}{ Eastern Mediterranean } \\
\hline lndeaths & 3707 & 2.080 & 1.542 & 0 & 6.186 \\
\hline lncases & 5161 & 5.096 & 2.224 & 0 & 9.55 \\
\hline \multicolumn{6}{|l|}{ Europe } \\
\hline lndeaths & 9029 & 2.235 & 1.676 & 0 & 7.602 \\
\hline lncases & 13,757 & 4.901 & 2.393 & 0 & 11.371 \\
\hline \multicolumn{6}{|c|}{ Southeast Asia } \\
\hline lndeaths & 1111 & 3.341 & 1.97 & 0 & 7.602 \\
\hline lncases & 2074 & 4.924 & 3.179 & 0 & 11.492 \\
\hline \multicolumn{6}{|c|}{ Western Pacific } \\
\hline lndeaths & 1279 & 1.513 & 1.34 & 0 & 7.162 \\
\hline lncases & 3149 & 3.393 & 2.296 & 0 & 9.626 \\
\hline
\end{tabular}

(a)

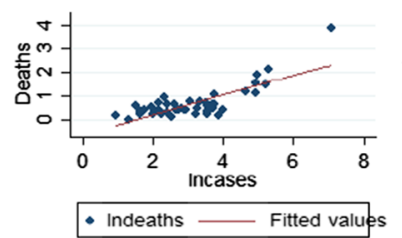

(d)

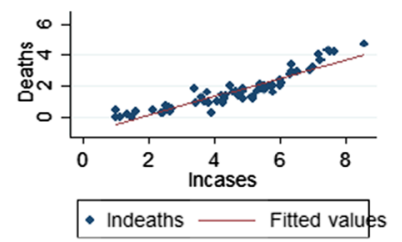

(b)

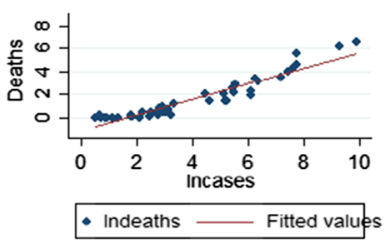

(e)

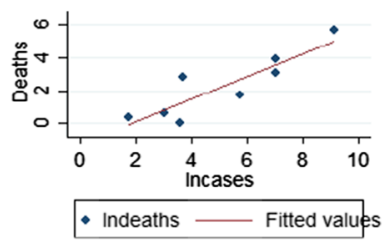

(c)

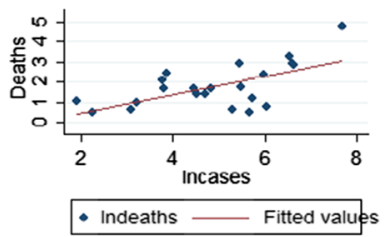

(f)

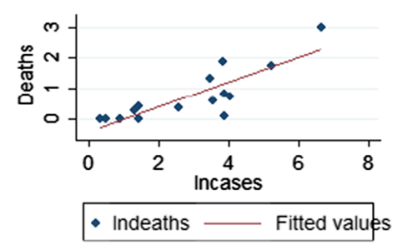

(g)

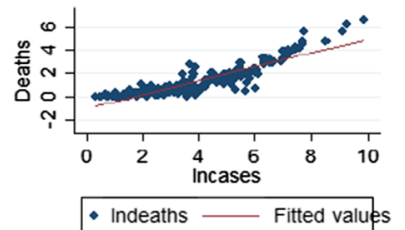

Fig. 2 Bivariate relationship between cases and deaths. a Africa, b Americas, c Eastern Mediterranean, d Europe, e Southeast Asia, f Western Pacific, g Global sample 
Table 2 IV-GMM results

\begin{tabular}{llllllll}
\hline Variable & $\begin{array}{l}\text { Model 1 } \\
\text { GLOBAL }\end{array}$ & $\begin{array}{l}\text { Model 2 } \\
\text { AFRICA }\end{array}$ & $\begin{array}{l}\text { Model 3 } \\
\text { AMERICAS }\end{array}$ & $\begin{array}{l}\text { Model 4 } \\
\text { EMT }\end{array}$ & $\begin{array}{l}\text { Model 5 } \\
\text { EUR }\end{array}$ & $\begin{array}{l}\text { Model 6 } \\
\text { SEA }\end{array}$ & $\begin{array}{l}\text { Model 7 } \\
\text { WTP }\end{array}$ \\
\hline lncases & $0.777 * * *$ & $0.648 * * *$ & $0.904 * * *$ & $0.667 * * *$ & $0.722 * * *$ & $0.876 * * *$ & $0.524 * * *$ \\
& $(0.004)$ & $(0.012)$ & $(0.007)$ & $(0.013)$ & $(0.006)$ & $(0.015)$ & $(0.017)$ \\
Constant & $-2.384 * * *$ & $-1.828 * * *$ & $-2.923 * * *$ & $-1.933 * * *$ & $-2.096 * * *$ & $-3.074 * *$ & $-1.188 * * *$ \\
& $(0.024)$ & $(0.058)$ & $(0.051)$ & $(0.080)$ & $(0.038)$ & $(0.125)$ & $(0.089)$ \\
Observations & 21,475 & 2495 & 4691 & 3375 & 8657 & 1069 & 1187 \\
r2 & 0.661 & 0.600 & 0.810 & 0.445 & 0.580 & 0.824 & 0.414 \\
rmse & 1.054 & 0.810 & 0.907 & 1.158 & 1.085 & 0.819 & 1.034 \\
F & $42,562.385$ & 2818.100 & $16,923.099$ & 2651.883 & $13,450.133$ & 3518.598 & 928.242 \\
j & 37.139 & 0.056 & 0.219 & 2.659 & 56.071 & 0.089 & 2.844 \\
jp & 0.000 & 0.813 & 0.640 & 0.103 & 0.000 & 0.766 & 0.092 \\
\hline
\end{tabular}

Incase COVID-19 confirmed cases, EMT Eastern Mediterranean, EUR Europe, SEA Southeast Asia, WTP Western Pacific. ()$=$ robust standard errors, $\mathrm{j}=$ Hansen J-statistics, $\mathrm{jp}=$ Hansen J-statistics $p$ value, $\mathrm{F}=\mathrm{F}$-statistics

${ }^{*} p<0.1, * * p<0.05, * * * p<0.01$

the Eastern Mediterranean, 0.72\% in Europe, $0.88 \%$ in South-East Asia and $0.52 \%$ in the Western Pacific. These results imply that a $10 \%$ rise in cases increases deaths by $6.5 \%$ in Africa, $9.0 \%$ in the Americas, $6.7 \%$ in the Eastern Mediterranean, $7.2 \%$ in Europe, $8.8 \%$ in Southeast Asia and 5.2\% in the Western Pacific. These results were not significantly different from the FE results (Table 3). However, the coefficients of the IVGMM estimator were slightly higher than the FE estimates, indicating that the IV-GMM model addresses endogeneity and omitted variable problems. The positive effect of cases on deaths is in line with our expectations and the findings of Sarkodie and Owusu (2020) and Adekunle et al. (2020). However, our coefficient of $0.65 \%$ in Africa differs from that of Adekunle et al. (2020). They found that a percentage increase in cases increases deaths by $0.045 \%$. These differences could be attributed to the differences in the

Table 3 Fixed effects results

\begin{tabular}{llllllll}
\hline Variable & $\begin{array}{l}\text { Model 1 } \\
\text { GLOBAL }\end{array}$ & $\begin{array}{l}\text { Model 2 } \\
\text { AFRICA }\end{array}$ & $\begin{array}{l}\text { Model 3 } \\
\text { AMERICAS }\end{array}$ & $\begin{array}{l}\text { Model 4 } \\
\text { EMT }\end{array}$ & $\begin{array}{l}\text { Model 5 } \\
\text { EUR }\end{array}$ & $\begin{array}{l}\text { Model 6 } \\
\text { SEA }\end{array}$ & $\begin{array}{l}\text { Model 7 } \\
\text { WTP }\end{array}$ \\
\hline lncases & $0.557 * * *$ & $0.381 * * *$ & $0.635 * * *$ & $0.646 * * *$ & $0.543 * * *$ & $0.683 * * *$ \\
& $(0.022)$ & $(0.060)$ & $(0.056)$ & $(0.046)$ & $(0.027)$ & $0.377 * * *$ \\
Constant & $-1.071 * * *$ & $-0.614 * *$ & $-1.181 * * *$ & $-1.780 * * *$ & $-1.021 * * *$ & $-1.643 * *$ & -0.425 \\
& $(0.128)$ & $(0.275)$ & $(0.358)$ & $(0.273)$ & $(0.163)$ & $(0.506)$ & $(0.473)$ \\
Observations & 23,362 & 3225 & 5120 & 3681 & 8965 & 1108 & 1261 \\
r2 & 0.438 & 0.288 & 0.505 & 0.575 & 0.397 & 0.782 & 0.255 \\
r2_w & 0.438 & 0.288 & 0.505 & 0.575 & 0.397 & 0.782 & 0.255 \\
r2_o & 0.659 & 0.555 & 0.800 & 0.452 & 0.580 & 0.822 & 0.411 \\
r2_b & 0.744 & 0.531 & 0.842 & 0.356 & 0.819 & 0.898 & 0.500 \\
rho & 0.412 & 0.326 & 0.492 & 0.640 & 0.236 & 0.689 & 0.364 \\
rmse & 0.814 & 0.640 & 0.728 & 0.671 & 0.958 & 0.515 & 0.860 \\
F & 663.819 & 39.843 & 129.325 & 201.498 & 401.389 & 97.232 \\
\hline
\end{tabular}

lncase COVID-19 confirmed cases, EMT Eastern Mediterranean, EUR Europe, SEA Southeast Asia, WTP Western Pacific. ()$=$ robust standard errors

${ }^{*} p<0.1, * * p<0.05, * * * p<0.01$ 


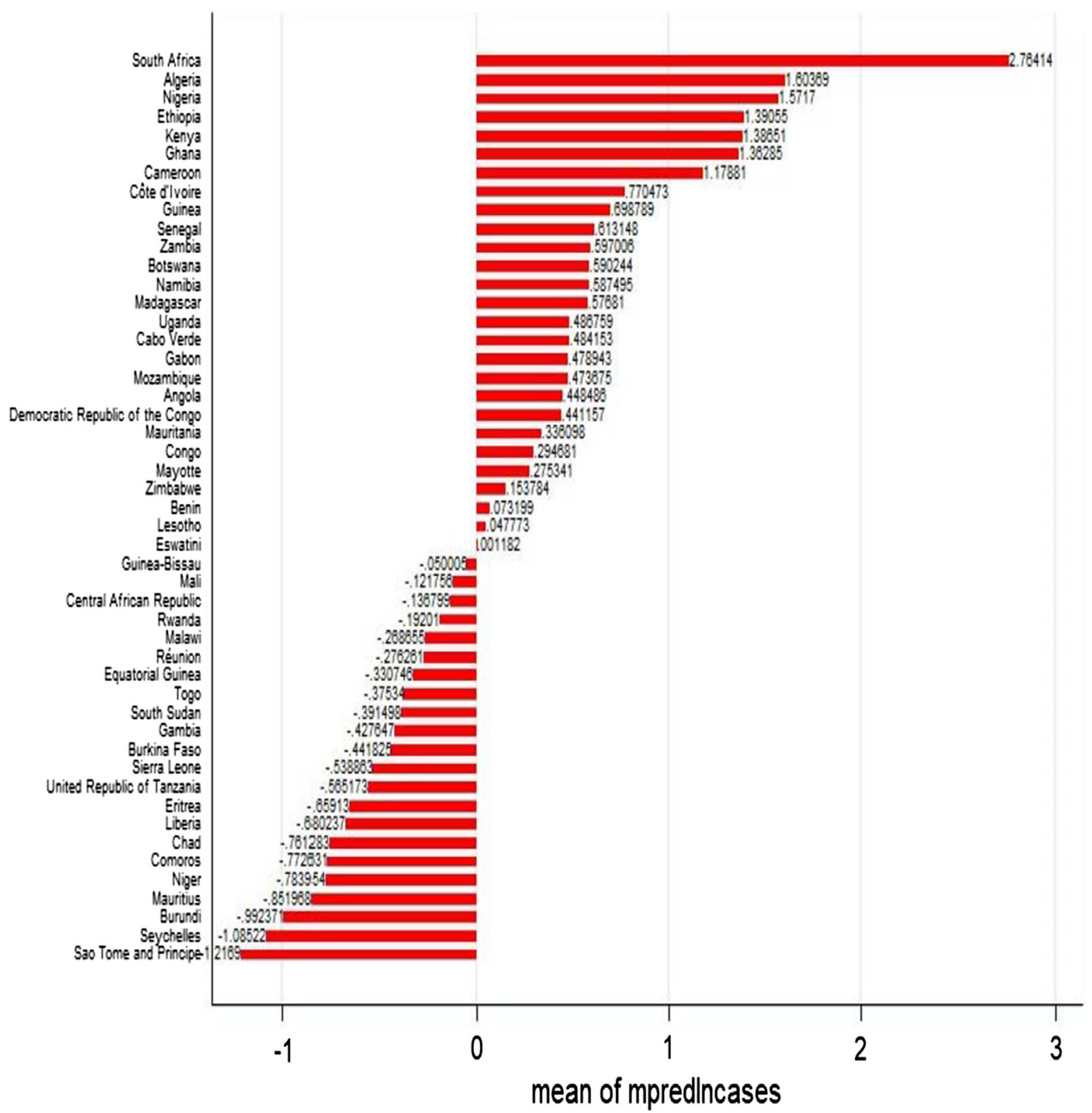

Fig. 3 Predicted effect of cases on deaths in Africa

period. Another reason may be because Africa has had a later spread of COVID-19 compared with other regions.

Comparatively, the results indicate that the Americas had the highest mortality rate of COVID-19 followed by South-East Asia, Europe, Eastern Mediterranean, Africa, with the Western Pacific having the lowest.
The IV-GMM model does not suffer from instrument over-identification given the probability value of the Hansen test, except Models 1 and 5. However, the F-statistics values show the instrument used are not weak. 


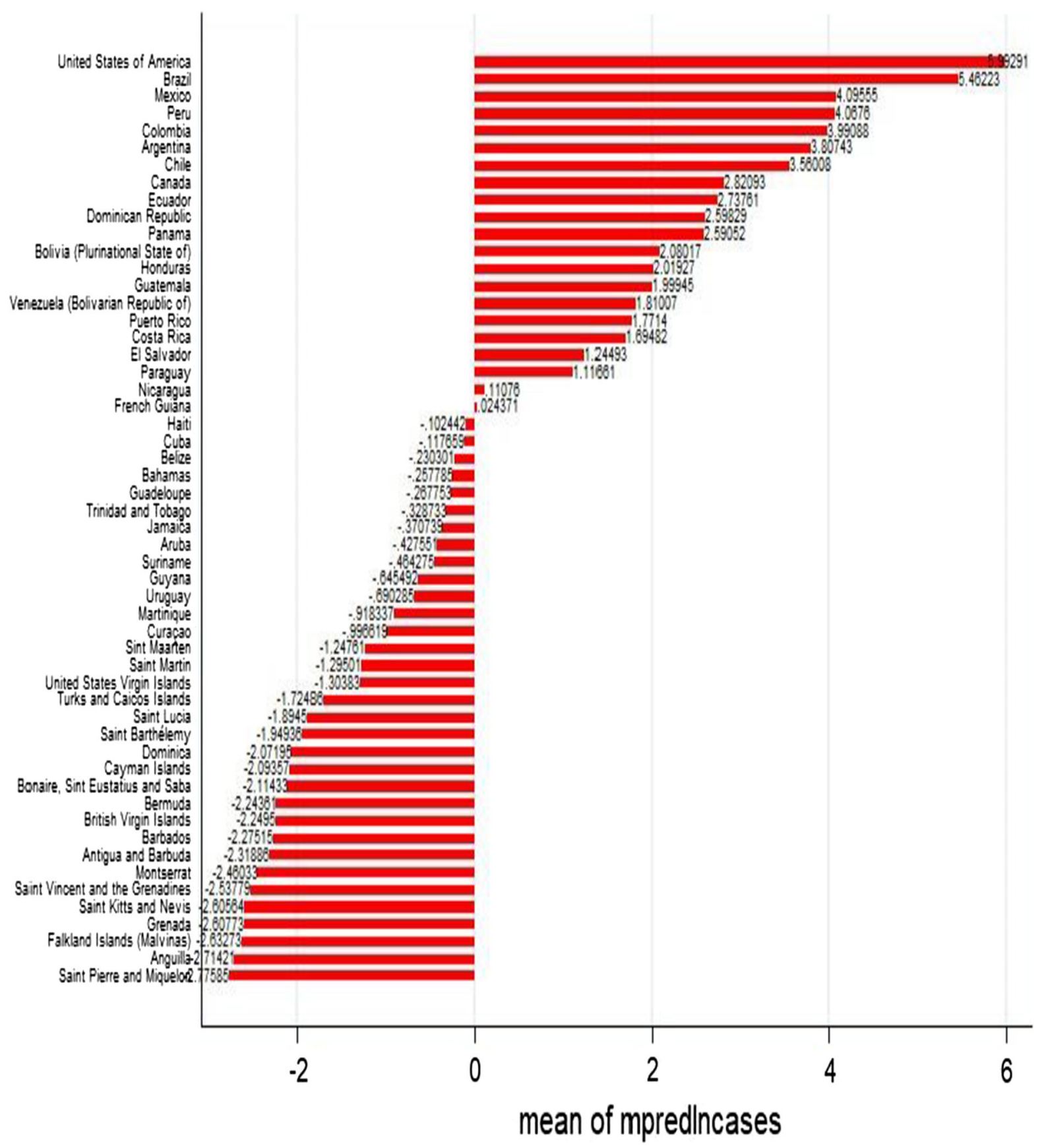

Fig. 4 Predicted effect of cases on deaths in the Americas

Regional analysis

Given the differences in cases globally, we further predict the individual country means based on the IVGMM results to make good policy decisions. Figures $3,4,5,6,7$, and 8 shows the predicted effect of cases on deaths. The results show vast differences in the impact of cases on deaths. In Africa (Fig. 3), South Africa, Algeria, Nigeria, Ethiopia, and Ghana had the highest effect of cases on deaths. On the contrary, the effect of cases on deaths was not severe in countries such as Sao Tome and Principe, Seychelles, Burundi, 


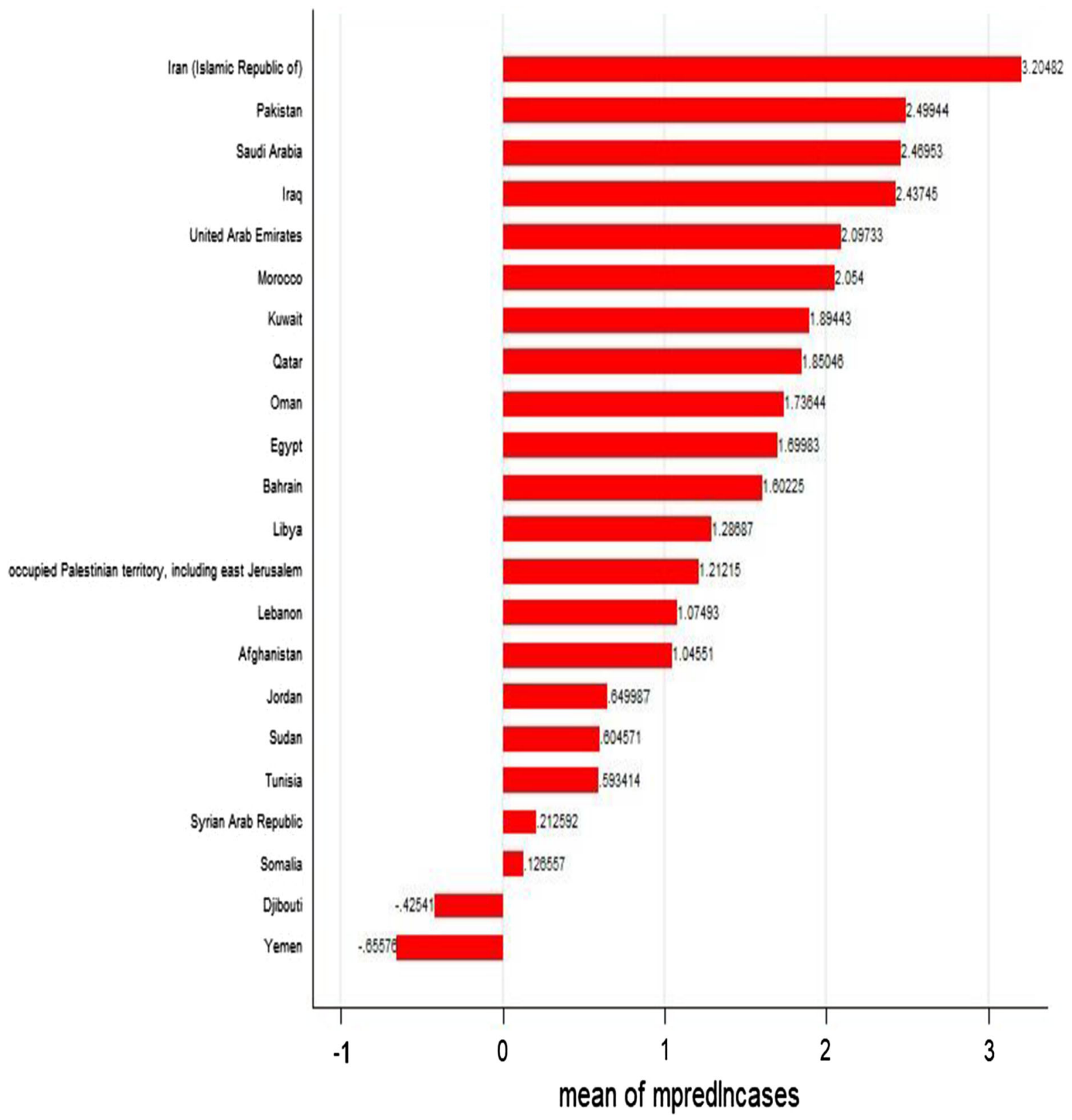

Fig. 5 Predicted effect of cases on deaths in the Eastern Mediterranean

Mauritius, and Niger. Figure 4 shows the predicted effect of cases on deaths in the Americas. The results show that the United States of America (USA), Brazil, Mexico, Peru, and Colombia had the highest effect of cases on deaths. In the case of the Eastern Mediterranean (Fig. 5), Iran, Pakistan, Saudi Arabia, Iraq, and the United Arab Emirates (UAE) had the highest effect of cases on deaths. In Europe (Fig. 6), Russia, Spain,
France, the United Kingdom (UK), and Turkey had the highest effect of cases on deaths. India, Indonesia, Bangladesh, Nepal, Myanmar had the highest effect of cases on deaths in Southeast Asia (Fig. 7). Finally, the Philippines, Japan, South Korea, Singapore, and Malaysia had the highest effect of cases on deaths in the Western Pacific (Fig. 8). The differential analysis of this kind is critical for specific policy focus for each 


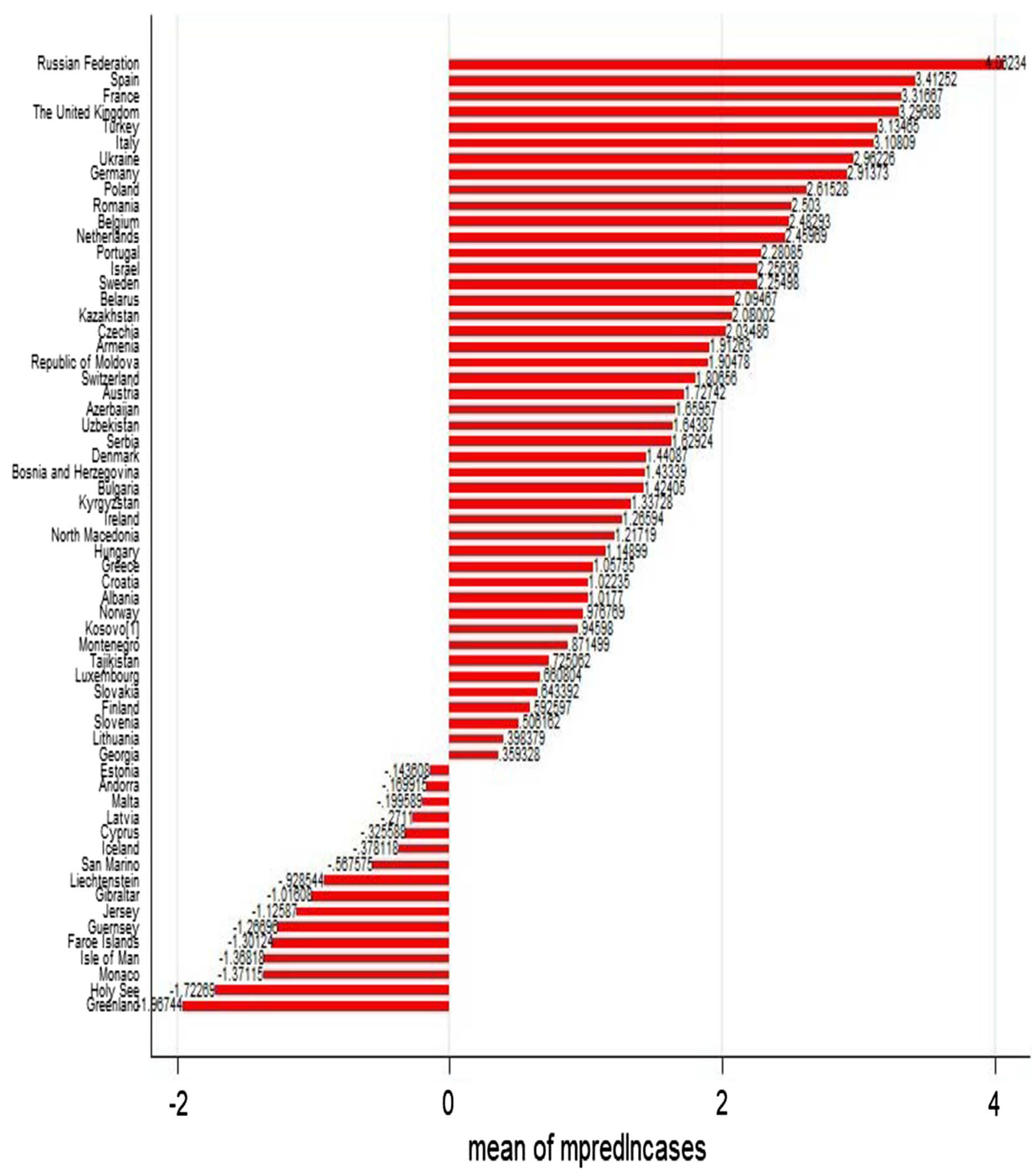

Fig. 6 Predicted effect of cases on deaths in Europe

country and region. This is because the analysis of the dynamics of virus and effective measures are important in the prevention of the pandemic (Aslam et al., 2021).

\section{Conclusion and policy recommendations}

This study's goal was to examine the effect of cases on deaths focusing on the global and regional levels. By using a panel of 232 countries (further disaggregated 


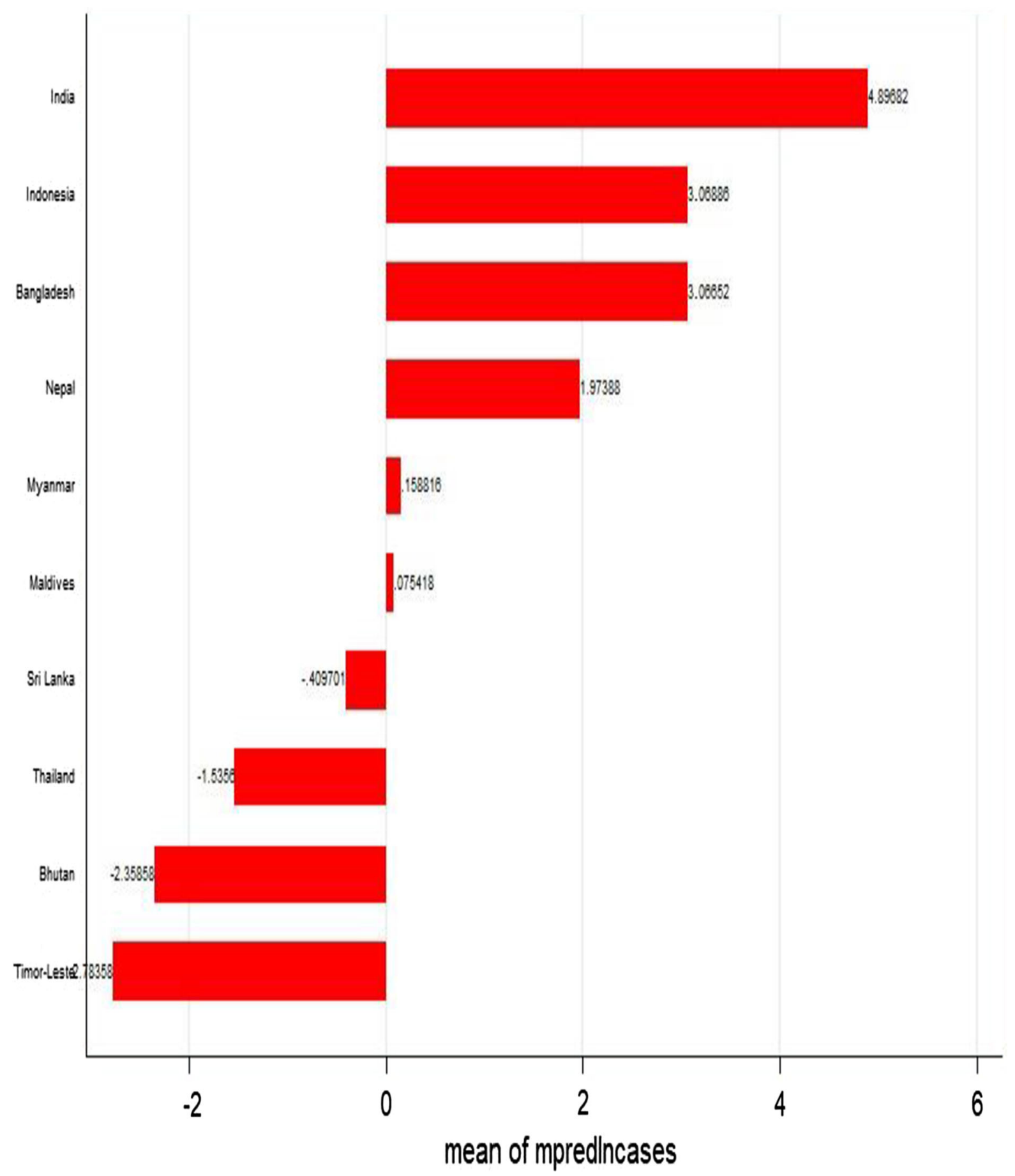

Fig. 7 Predicted effect of cases on deaths in Southeast Asia

into Africa-49, Americas-54, Eastern Mediterranean23, Europe-61, Southeast Asia-10, and Western Pacific-35) from 03 January 2020 to 28 November 2020 and the IV-GMM model, we found cases to significantly increase deaths in both the global and regional levels.

We further found that the death rates of COVID-19 were high in the Americas, Southeast Asia, and 


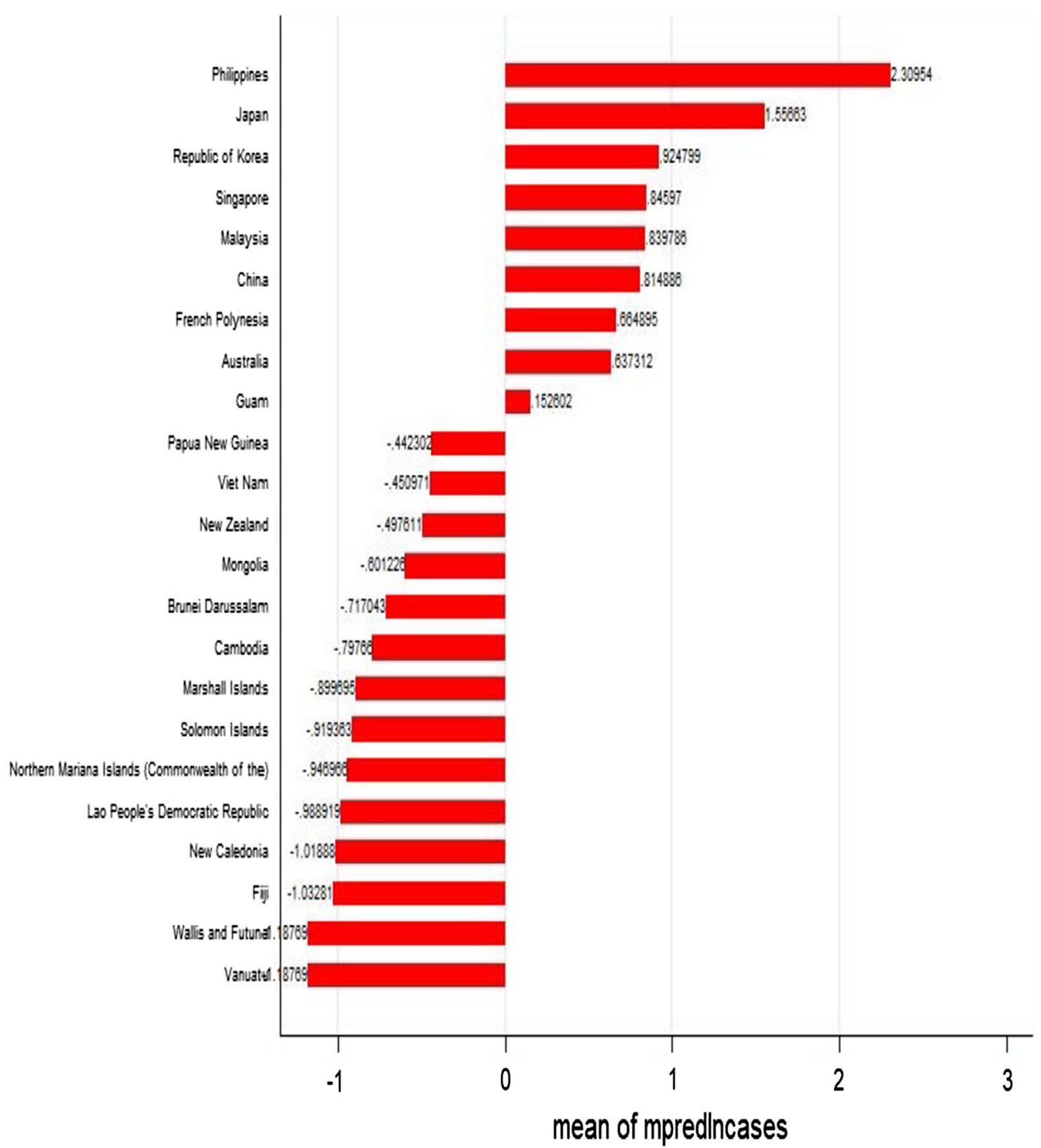

Fig. 8 Predicted effect of cases on deaths in the Western Pacific

Europe as compared to the Eastern Mediterranean, Africa, and the Western Pacific. However, this is not a safety assurance to regions and countries with low death rates. Global temperature is important in the transmission mechanism of the virus. With the variability of temperature due to seasonal changes, countries and regions can switch from one state of vulnerability to another. With the on-going changes in the season or temperature variability and the second wave of the virus, some of these regions especially Africa, which hitherto had lower cases and deaths are experiencing steadily increasing rates in recent times. 
This is observable in the current daily cases and deaths on the WHO Dashboard. Coincidently, these regions have some of the poorest countries and health systems (e.g., Africa). With a poorer health system, these countries might be particularly hit the hardest should the cases sprung out of proportion or at the level experienced in other regions or countries.

Accordingly, the study recommends the public to adhere to the WHO preventive measures in all regions, including those that exhibited lower death rates in this study. These measures include regular washing of the hands with running water and soap, maintain personal hygiene, avoid touching of the eyes and mouth, maintain social distancing, and personally isolate with mild fever and coughs to reduce the human-to-human transmission. Moreover, policymakers should improve health systems by channelling resources to the health sector. Policies and programmes to provide access to vaccines to all regions and countries, including the poorer ones, must be implemented effectively. On this, the current COVAX Facility that aims to ensure all countries have access to a safe and effective vaccine is a worthy enterprise. This should be made effective and accessible to all countries. Furthermore, medical and financial support should be extended to hard-hit countries and citizens to reduce the poverty associated with this pandemic. Finally, we recommend countries unite by pooling resources together to help combat this pandemic.

Author contributions IA-O: Conceptualization, writing, review, editing, formal analysis, data curation, software, validation. MBK: Conceptualization, writing, review, editing, validation, drawing of map.

\section{Declarations}

Conflict of interest We declare there is no conflicts of interest.

Human and animal rights The article does not contain any studies with human or animal subjects.

\section{References}

Acheampong, A. O., Adams, S., \& Boateng, E. (2019). Do globalization and renewable energy contribute to carbon emissions mitigation in Sub-Saharan Africa? Science of the Total Environment, 677, 436-446. https://doi.org/10.1016/ j.scitotenv.2019.04.353
Adekunle, I. A., Onanuga, A. T., Akinola, O. O., \& Ogunbanjo, O. W. (2020). Modelling spatial variations of coronavirus disease (COVID-19) in Africa. Science of the Total Environment, 729, 138998. https://doi.org/10.1016/j.scitotenv. 2020.138998

Ahmadi, M., Sharifi, A., Dorosti, S., Jafarzadeh Ghoushchi, S., \& Ghanbari, N. (2020). Investigation of effective climatology parameters on COVID-19 outbreak in Iran. Science of the Total Environment, 729, 138705. https://doi.org/10. 1016/j.scitotenv.2020.138705

Appiah-Otoo, I., \& Acheampong, A. O. (2021). Does insurance sector development improve environmental quality? Environmental Science and Pollution Research. https://doi. org/10.1007/s11356-021-12760-w

Appiah-Otoo, I., \& Song, N. (2021). The impact of ICT on economic growth-comparing rich and poor countries. Telecommunications Policy, 45(2), 102082. https://doi. org/10.1016/j.telpol.2020.102082

Aronu, C. O., Ekwueme, G. O., Sol-Akubude, V. I., \& Okafor, P. N. (2021). Coronavirus (COVID-19) in Nigeria: Survival rate. Scientific African, 11, e00689. https://doi.org/10. 1016/j.sciaf.2020.e00689

Aslam, M., Farman, M., Akgül, A., \& Su, M. (2021). Modeling and simulation of fractional order COVID-19 model with quarantined-isolated people. Mathematical Methods in the Applied Sciences. https://doi.org/10.1002/mma.7191

Bashir, M. F., Ma, B., Komal, B. B., Bashir, M. A., Tan, D., \& Bashir, M. (2020a). Correlation between climate indicators and COVID-19 pandemic in New York, USA. Science of the Total Environment, 728, 138835. https://doi.org/10. 1016/j.scitotenv.2020.138835

Bashir, M. F., Ma, B. J., Komal, B. B., Bashir, M. A., Farooq, T. H., Iqbal, N., \& Bashir, M. (2020b). Correlation between environmental pollution indicators and COVID-19 pandemic: A brief study in Californian context. Environmental Research, 187, 109652. https://doi.org/10.1016/j.envres. 2020.109652

Coccia, M. (2020). Factors determining the diffusion of COVID-19 and suggested strategy to prevent future accelerated viral infectivity similar to COVID. The Science of the Total Environment, 729, 138474. https://doi.org/10. 1016/j.scitotenv.2020.138474

Cunningham, G. B. (2021). Physical activity and its relationship with COVID-19 cases and deaths: Analysis of U.S. counties. Journal of Sport and Health Science. https://doi.org/ 10.1016/j.jshs.2021.03.008

Desjardins, M. R., Hohl, A., \& Delmelle, E. M. (2020). Rapid surveillance of COVID-19 in the United States using a prospective space-time scan statistic: Detecting and evaluating emerging clusters. Applied Geography, 118, 102202. https://doi.org/10.1016/j.apgeog.2020.102202

Gaskin, D. J., Zare, H., \& Delarmente, B. A. (2021). Geographic disparities in COVID-19 infections and deaths: The role of transportation. Transport Policy, 102, 35-46. https://doi. org/10.1016/j.tranpol.2020.12.001

Huang, B., Zhu, Y., Gao, Y., Zeng, G., Zhang, J., Liu, J., \& Liu, L. (2021). The analysis of isolation measures for epidemic control of COVID-19. Applied Intelligence. https://doi.org/ 10.1007/s10489-021-02239-z

Jabłońska, K., Aballéa, S., \& Toumi, M. (2021). Factors influencing the COVID-19 daily deaths peak across European 
countries. Public Health. https://doi.org/10.1016/j.puhe. 2021.02.037

Jain, M., Sharma, G. D., Goyal, M., Kaushal, R., \& Sethi, M. (2021). Econometric analysis of COVID-19 cases, deaths, and meteorological factors in South Asia. Environmental Science and Pollution Research. https://doi.org/10.1007/ s11356-021-12613-6

Kodge, B. G. (2021). A review on current status of COVID19 cases in Maharashtra state of India using GIS: A case study. Spatial Information Research, 29(2), 223-229. https://doi. org/10.1007/s41324-020-00349-3

Magazzino, C., Mele, M., \& Sarkodie, S. A. (2021). The nexus between COVID-19 deaths, air pollution and economic growth in New York state: Evidence from deep machine learning. Journal of Environmental Management, 286, 112241. https://doi.org/10.1016/j.jenvman.2021.112241

Ma, Y., Zhao, Y., Liu, J., He, X., Wang, B., Fu, S., Yan, J., Niu, J., Zhou, J., \& Luo, B. (2020). Effects of temperature variation and humidity on the death of COVID-19 in Wuhan, China. Science of the Total Environment, 724, 138226. https://doi.org/10.1016/j.scitotenv.2020.138226
Roy, I. (2020). The role of temperature on the global spread of COVID-19 and urgent solutions. International Journal of Environmental Science and Technology. https://doi.org/10. 1007/s13762-020-02991-8

Sarkodie, S. A., \& Owusu, P. A. (2020). Investigating the cases of novel coronavirus disease (COVID-19) in China using dynamic statistical techniques. Heliyon, 6(4), e03747. https://doi.org/10.1016/j.heliyon.2020.e03747

Sharma, P., Singh, A. K., Agrawal, B., \& Sharma, A. (2020). Correlation between weather and COVID-19 pandemic in India: An empirical investigation. Journal of Public Affairs, 20(4), e2222. https://doi.org/10.1002/pa.2222

Yahya, B. M., Yahya, F. S., \& Thannoun, R. G. (2021). COVID19 prediction analysis using artificial intelligence procedures and GIS spatial analyst: A case study for Iraq. Applied Geomatics. https://doi.org/10.1007/s12518-02100365-4

Publisher's Note Springer Nature remains neutral with regard to jurisdictional claims in published maps and institutional affiliations. 